\title{
Narratives of an Outsourced Information Systems Failure in a Small Enterprise
}

\author{
Jan Devos, Hendrik Van Landeghem, and Dirk Deschoolmeester \\ Ghent University, Belgium \\ \{jang.devos, hendrik.vanlandeghem, \\ dirk.deschoolmeester\} @uGent. be
}

\begin{abstract}
In this study we investigate a case of an outsourced information systems (IS) failure (OISF) within the collaborative partnership among asymmetric partners. A small and medium-sized enterprise (SME) is dealing with an independent software vendor (ISV) conducting a project of implementing an IS that fails. We used a narrative research methodology for our enquiry. In the construction of our narrative we followed the OISF framework as a theoretical touchstone. As a major conclusion we found that asymmetric collaborations with partners with inadequate managerial and technical IT capabilities are extremely prone to OISF's. We showed that an outcome-based and fixed price contract is not an adequate instrument to conduct such a partnership and to avoid a failure.
\end{abstract}

Keywords: IT/IS, failures, OISF framework, case study, narrative methodology, trust, contracts, principal-agent.

\section{Introduction}

Although the phenomenon of IS failures is well known in both IT practitioners and scholar communities, there is still little known that helps to decrease the associated concerns (Group 2004; Verner et al. 2012). To our best knowledge research on IS failures tend to be scattered and too much focused on projects conducted in mature and large organizations and too little on a deep understanding of what small and medium-sized enterprises (SMEs) with lower managerial and technical IT capabilities drive to adopt information systems (Avison et al. 2006; Bartis et al. 2008; Conboy 2010; Kreps et al. 2007). We focus here on an IS failure in an SME.

Although SMEs do not constitute a homogenous group of (smaller) organizations, when it comes to implementing information systems, most of them depend on an ISV (Devos et al. 2012). SMEs do not have as much resources (e.g. financial, material and knowledge) than large organizations (Welsh et al. 1981). This can be noticed in the absence of an IS function in SMEs, but also in the lower level of IT adoption (Antlova 2009; Bruque et al. 2007). Nor is there a clear and comprehensive vision on what information systems could mean within these organizations (Cragg et al. 1993; Huang et al. 2010). Most of the decision making in SMEs is centred around the CEO, which is often an entrepreneur who does not make a separation between ownership (governance) 
and control (management) in his organization (Lefebvre et al. 1997; Levy et al. 2005; Thong et al. 1995). This can be good or bad. Well committed CEOs can establish the critical success factors for avoiding IS failures (Admiraal et al. 2009). However there are still IS failures with committed CEOs to be noticed, mainly due to poor managerial and technical IT skills (Devos et al. 2012). Within the large set of IS failures we focus here on the outsourced IS failure (OISF). An OISF is a failure that arises during an IS project in an outsourced environment (Devos et al. 2008).

This paper is structured as follows: in section 2, we elaborate on the concept and framework of OISFs. In section 3 we bring a summary of our research method is presented. Section 4 bring the narrative of an OISF. Finally in section 5 we bring our conclusions.

\section{Outsourced IS Failures}

IS failures can be divided in expectation (Lyytinen et al. 1987) and termination (Sauer 1993) failures. Expectation failures can be categorised in correspondence, process and interaction failures. Correspondence failures happen when IT artefacts are evaluated towards previous defined design objectives. A lack of correspondence between design objectives and evaluation is seen as a failure. Process failures arise when there is unsatisfactory development performance, i.e., one fails to produce a workable system or to deliver within the budget constraints of time and costs. Process failures are sometimes becoming 'runaways' or escalating projects (Iacovou et al. 2005; Keil 1995). Interaction failures are situated within the mismatch between requirements and user acceptance. An interaction failure appears when an IT artefact is not used.

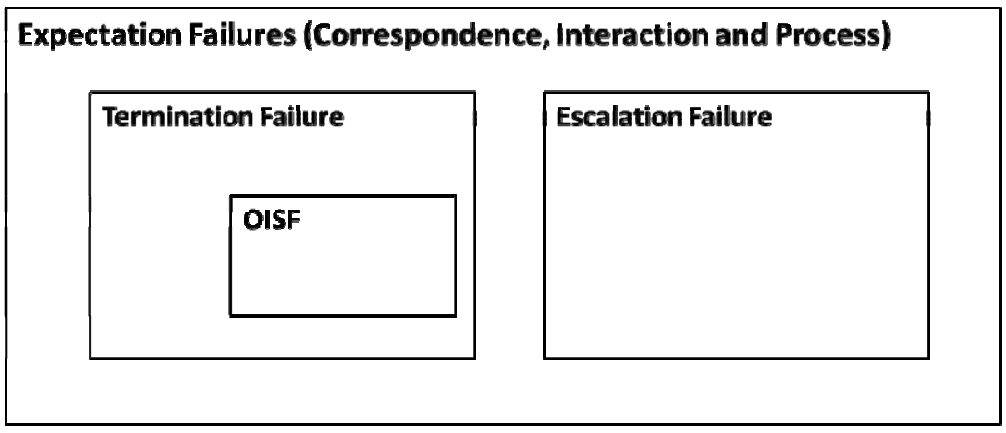

Fig. 1. A classification of IS failures

In summary, an IS expectation failure is the inability of an IS to meet the expectations of the stakeholders. Sauer brought up the more pragmatic concept of the termination failure (Sauer 1993). According to Sauer an IS failure can only occur when the development process or operation of an IS causes dissatisfied stakeholders to abandon the project. There is an extra dimension to IS failures that is not covered by those descriptive models, which is called the Outsourced IS Failure (OISF). An OISF is a failure that arises during an IS project in an outsourced environment. We use the taxonomy of Lacity and Hirschheim of outsourcing options and focus on Project Management 
(Dibbern et al. 2004). So OISF's are a subset of process failures within the expectation failures category of Lyytinen \& Hirschheim (Lyytinen et al. 1987). In figure 1 we give a illustrative overview of the classification of IS failures.

When two parties find each other in a outsourced IS project governed by a principal-agent setting some dynamics must be taken into account (Eisenhardt 1989; Jensen et al. 1976). We consider here an SME-principal, represented by the CEO and an ISVagent represented by the CEO in the role of the sales representative. The SMEprincipal is in search for an ISV who can implement a strategic information system (e.g. ERP, CRM, SCM) in his organization. This is a typical case of a bidirectional asymmetric relationship which should move into an asymmetric collaboration. With a decision of this kind and magnitude serious risks are involved that most likely will affect the outcome of the project. Some academics have pointed out that outsourcing increases risks leading to IS failures (Aubert et al. 2003; Natovich 2003). These risks are related to human behaviour, organizational and project management issues (Schmidt et al. 2001). Devos et al (2009) have developed a framework to describe the OISF (Devos et al. 2009a). This framework is presented in figure 2.

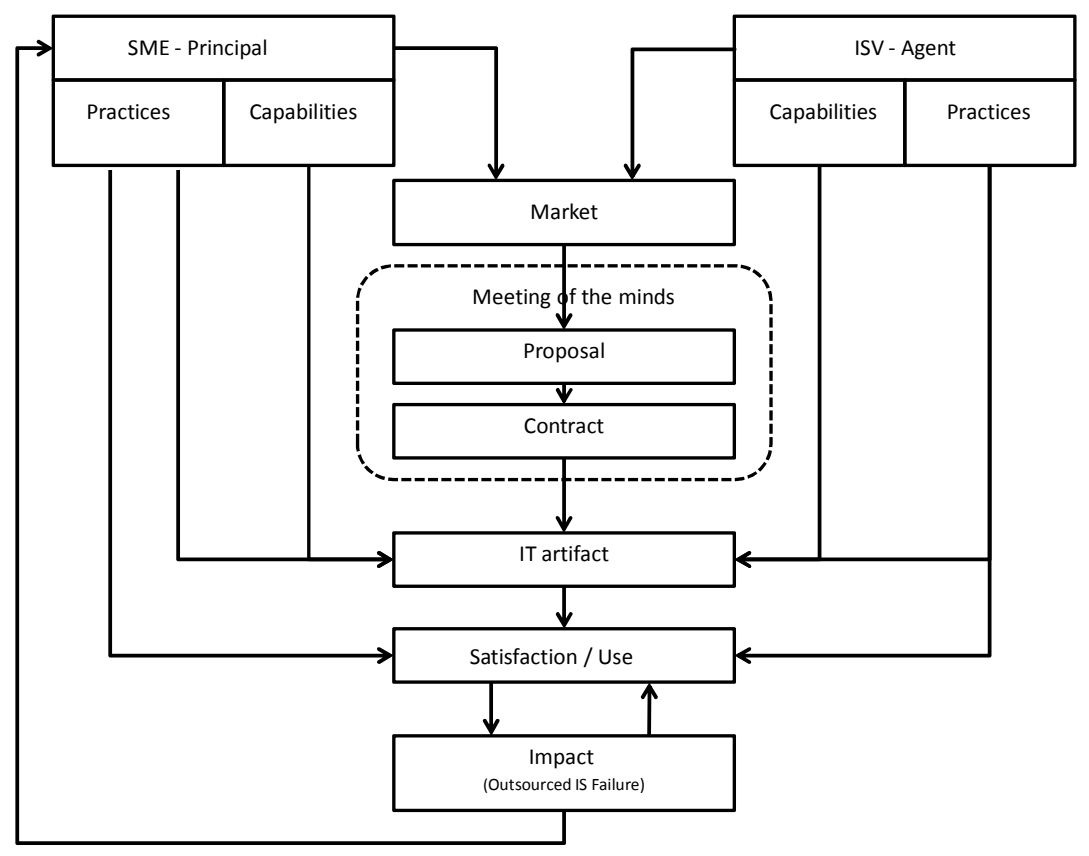

Fig. 2. The Outsourced IS Failure framework

The OISF elaborates on the findings of Lyytinen and Hirschheim on IS failures and is based on the construct of IS use and IS development as the foci of organisational action (Lyytinen et al. 1987). These concepts were partly recycled in the concept of the IT artefact and its immediate nomological net or IS-net developed by Benbasat 
et al. (Benbasat et al. 2003). Consecutively, the nomological net was further refined by Gable et al. by bringing in constructs from the Delone and McLean IS Success model (DeLone et al. 2003; Gable et al. 2008). The interrelated constructs of the OISF framework are:

- a risk-neutral SME-principal with managerial, methodological and technological capabilities and practices for planning, designing, and implementing IT artefacts;

- a risk-averse ISV-agent with managerial, methodological and technological capabilities and practices for planning, designing, and implementing IT artefacts;

- $\quad$ a market where SME-principals and ISV-agents meet each other;

- a meeting-of-the-minds where SME-principals and ISV-agents establish a contract;

- $\quad$ an IT artefact, which is a human construction, utilitarian and not neutral;

- the use of the IT artefact, including a development and implementation trajectory;

- the impact of the IT artefact on the organization, whether direct or indirect, intended or unintended. An OISF is considered to have an impact on the organization.

The motivation for using the OISF framework is twofold. First it is to our best knowledge the only framework that deals in a specific way with the constructs of an outsourced project in a heavily asymmetric setting of a less informed principal (SME) and a well-informed agent (ISV). Outsourced projects constitute the majorities of projects (and failures) conducted in an SME. Second, the framework has a high internal and external validity. Since the framework is built around existing frameworks and theories it has well spelled out constructs, each of them often validated in separate settings. The framework seems to offer opportunities for empirical validating, both from positivistic as well as from a interpretative way. The OISF framework offers a theoretical and descriptive structure with measurable constructs and with the potential to derive propositions. However in this work we are opting for a more interpretative approach for our inquiry and will not conduct a hypothesis testing research. Our research question for this inquiry is: Can the OISF framework act as a theoretical guidance to explain the observed facts in a situation of an IS failure in an SME?

\section{$3 \quad$ Research Method}

We choose to use a narrative research methodology for our enquiry (Riessman 1993). Although this methodology is seen as a valid approach within the large variety of qualitative IS research methods (Myers 1997), the use in IS research and particularly on IS failures is rather limited (Bartis et al. 2008; Brown et al. 1998; Davidson 1997; Fincham 2002; Wagner 2003; Webb et al. 2007). According to Webb and Mallon (2003) narrative analysis is becoming more important to IS research. We argue that the method of telling stories is indeed underestimated and largely suitable for research on IS failures. The phenomenon of an IS failure is complex, multifaceted and constitutes an amalgam of technological, methodical, and social constructs which are not 
easy if possible at all, to be analysed separately (Lyytinen et al. 1987). We argue that an IS failure is largely the outcome of the human mind. Narratives provide us a way to create a shareable understanding of social-technical phenomena. We organize our experience of human happenings mainly in the form of narratives - stories, excuses, myths, and reasons for doing and not doing (Bruner 1991). Positivistic assumptions from natural sciences alone prove little to understand socio-technical systems. Many IS researchers pleaded therefore already for a pluralist approach in our field (Lee 1999; Mingers 2001; Weber 2004). However al lot of research on IS failures has concentrated on deficits in the process of developing and implementing information systems or on the root causes of failure but less on meaning or sense making of the concept of an IS failure (Barker et al. 2003; Beynon-Davies 1999; Cerpa et al. 2009; Chen et al. 2009; Cule et al. 2000; Ewusi-Mensah 2003; Sauer 1993). Therefore we need a research approach that offers us the possibility to deal with the complexity of the phenomenon as a whole, instead of working by means of a reduction of reality.

A narrative is an interpretation of events that constitutes the core of organizational knowledge and reflects the significance organizational issues that actors seek to dramatize (Czarniawska 1997). In its essence a narrative is defined as a 'tale, story, and recital of facts especially a story told in the first person' (Myers 1997). Narratives or story telling is to be seen as a metaphor for creating order and to construct text that brings a rich description for a complex phenomenon in a particular context (Riessman 1993). The narrative is idiographic in nature and therefore generalizability is difficult to obtain. We are inspired by the same challenges of generalizability of IS research in general and within the case study research in particular (Eisenhardt 1991; Lee et al. 2003; Yin 2003). We apply the case study research and try to bring as much as possible empirical (primary) data into the narrative. This implies that we have used multiple sources of data. To build up the narrative we used a real case of an outsourced IS failure in an SME. The case was well documented since it was subject to litigation. It is an typical example of a termination failure (Sauer 1993).The SME-principal ordered an information system with an ISV-agent and his expectations are not fulfilled. Therefor a court order was requested to obtain a contract dissolution. We collected all the primary data from the expert witness who was assigned to give advice on the failure to the court. Litigation files are most useful for scientific research, since they are well documented and they come from multiples sources (e.g. plaintiff and defender) which constitutes already a triangulation of the empirical data. We also had several interviews with the expert witness, which was an extra source of data. Although the expert opinion itself was a well-used source as an official document brought before court, we did not strive for alignment with the findings of the expert witness. The expert opinion offers only answers to questions raised by the court. Our purpose was pure academic within a quest for knowledge on IS failures. Although we maintained the same rigor of the positivistic case study research (Dube et al. 2003), our method is not positivistic in nature, but tend to be more interpretive (Walsham 1995). Our work is inspired by the work of Wagner et al. (2004) (Wagner et al. 2004). So we kept a theoretical stance in mind. During the building of the narrative, we investigated the validity of the OISF framework as a guidance to reveal a meaning of the OISF. Although we build the narrative with the guidance of a theoretical concept our conclusions in terms of generalization of the findings can go no further than the case itself. 


\section{The Narrative of an OISF}

\section{SME Principal: Blackbird Inc.}

Blackbird Inc. is a small enterprise selling and servicing brown and white goods mainly on a domestic market. Being a small company Blackbird is also selling products which are all closely related with brown and white goods, like electrical installation kits, tools, and even computers. The company is also offering services like installation projects, repairs and maintenance. The company has an inventory of spare parts of the products they sell. Sales goes directly through their stores. There is one main store and one outlet store a few tens of kilometres from the main store to service a local market over there. The customers are local residents, do-it-yourselves and small companies. So there is a wide variety in the sales administration. Direct sales goes over the counter desk with direct payments, cash or by wire. But there is also more indirect sales through sales orders received by telephone, fax or e-mail and delivered by own firm vans on regulars schedules.

Blackbird was founded by Mr \& Mrs Vanderbilt, husband and wife, both are playing an active and important role in their company. Mrs Vanderbilt takes care of the (direct) sales and the purchase. Mr Vanderbilt conducts the projects, the indirect sales and the service operations (repair, maintenance). The staff is very limited and is working in the stores. But there are three people working in the order department and there is an internal accountant. There is also a part-time IT manager, who is mainly doing technical tasks and duties as installing routers, PC and printers.

\section{ISV Agent: Andreas Inc.}

Andreas is a small local ISV. The company is not a business partner of a larger software supplier (e.g. Microsoft, Oracle, SAP) but develops bespoke applications. Their mission is to develop software for complex business processes. Although Andreas asserts that a Scrum methodology (Schwaber 2009) is applied for customer projects, a more waterfall development method is more be noticeable in their practices. According to their website Andreas offers also advice, support and training as separate service offerings. The company is young (founded in 2004) and has a staff of only four people which included the two founders at the time they met Blackbird. Andreas is steadily growing in staff and turnover and collected some nice sales references of realized software projects. These projects all seems to be very small and rather isolated and not within the core of what typical constitutes an ERP system. Examples of realized projects are: reporting projects, interfacing projects, and standalone web applications. There is no indication that Andreas has a lot of experience with the development and implementation of ERP-like applications, nor do they have an experienced staff in business processes and project management aside from the CEO's.

\section{Meeting of the Minds}

At a certain moment the principal and the agent will have a meeting of the minds. This is the moment where both parties are willing to contract. Both parties are now arrived at a mutual level of understanding and trust. 
Blackbird was in search for a new information system to support their growing business needs. The current Unix system has run out of his limits and it was time for a modern Windows-based computer system. Mr and Mrs Vanderbilt spoke about a Windows-based computer system as the archetype of a contemporary graphical user interface, with mouse and rich features on the clients workstation.

First Mr \& Mrs Vanderbilt consulted with the help of the IT manager, a major ERP vendor distributing and implementing Microsoft software. However they soon found out that the price for such a system was far above their planned budget. At that time Mrs Vanderbilt remembered a nice gentlemen in IT that she met and talked to on a reception of the local society of entrepreneurs. For her this looked as a trustful and skilled person. She got his business card and made a phone call to ... Andreas.

Both parties met and problems were discussed. Andreas accepted the challenge to go for a tender offering a good and cheap solution for Blackbird.

\section{Proposal}

The tender of Andreas was a document of five pages containing: 1) the context, 2) the architecture, 3) a project plan, 4) a fixed price and 5) some concluding remarks. The proposal reflects largely the sphere of trust that exist between the two parties. The proposal was edited in very positive way and revealed no possible risks that could arise during a collaboration between the parties. It was framed in a way that Blackbird could be at ease while Andreas would take care of almost everything going from requirements analysis to training and delivery. At this embryonic moment of the project trajectory trust between the collaborating parties was of major importance. Trust is the only mechanism that Blackbird as the unformed principal had at its disposal. This was well understood by Andreas. It was also clear that Blackbird was not willing to make the cost of reduce the information asymmetry with Andreas.

In the context section of the tender, Andreas states that the existing system was only briefly evaluated and that only two elements came out to motivate the acquisition of a new information system. The first element was the lack of support for the current system platform and continuity of the used technology (Unix). The second element was the poor and expensive support for the existing application. Andreas choose for a bespoke application for Blackbird. Although Andreas explicitly mentioned the limited information on the functional requirements, they take the risk for the assignment, stating that extra analysis will be needed during the course of the project. This proposed solution fulfil the first motivational element for a new information systems. To achieve the second element, the lack of platform support, Andreas called in the help of a third party with necessary skills and expertise on the chosen Microsoft platform.

The software architecture in the proposal of Andreas is described in half a page and refers only to two components: a client administration application (CAA) and a server application (SA). The CAA has six functional domains: client administration, supplier administration, product administration, purchase orders, sales orders and system administration. None of these functional domain is spelled out in more detail except for 
their title identification. The SA paragraph is even shorter: only two sentences. The first sentence is describing a procedure of servicing maintenance orders and a very short sentence describing the actions needed for material handling in the warehouse.

The project plan is a one page sheet containing the project start date (16-06-2008), the project end date, being also the final delivery date (9-9-2008), the total number of programming, analysing, testing and implementation days (90 men days), the allocated staff (4 persons: A, B, C and D). The project has a work breakdown structure of 45 detailed tasks, each of them having a start and end date and an amount of budgeted work expressed in hours or days. None of the detailed tasks has a description in depth of the work or actions to be done.

The fourth part of the proposal is a fixed price of $€ 55.000$ for the complete project. Although this is not mentioned in the proposal, it could be derived that Andreas has an average tariff of €611.11 for one day of work. The proposal also states that hardware, manuals and extra training is not included in the price. Manuals are not necessary according to Andreas and a basic training is incorporated in the initial project offering.

Finally there are some concluding remarks in the proposal. First of all, Andreas repeats its offer that hardware is not included in the price. there are also three statements concerning the application. First is a statement concerning the property rights of the software (source code) that goes entirely to Blackbird. Secondly there is a statement on the unlimited number of users and servers that can be applied to the application. And finally a maintenance contract on the software is possible but not obligatory. Andreas closed the document with the remark that some explanation is needed with the offerings.

\section{Contract}

Both parties did not take too much time to contract. The initial proposal was entirely kept as the basis for the contract negotiations. So an agreement based on the proposal and on the oral explanation of the sales representative (the CEO) was settled and the contract was signed. The contract specifies a fixed price of €55.000, as mentioned in the proposal. Both parties felt quite optimistic about the endeavour that was to take off.

\section{IT Artefact}

According to Andreas the IT artefact was developed with the use of a Scrum approached (Schwaber 2009). There were seven sprint cycles, all equally having a planned timeframe of one month. In table 1 the initially contracted and planned sprint cycles (first column) and the ex post executed sprint cycles (second column) are shown. The third columns shows the deviation in days between what was planned and what actually happened.

After each sprint cycle an invoice was made by Andreas, send to Blackbird and almost immediately paid, as agreed in the contract. 
Table 1. Overview of the Scrum Sprint Cycles

\begin{tabular}{|c|c|c|}
\hline Planned Sprint Cycle & Executed Sprint Cycle & $\begin{array}{c}\text { Deviation } \\
\text { (days) }\end{array}$ \\
\hline $31 / 05 / 2008$ & $31 / 05 / 2008$ & 0 \\
\hline $30 / 06 / 2008$ & $30 / 06 / 2008$ & 0 \\
\hline $31 / 07 / 2008$ & $25 / 07 / 2008$ & 33 \\
\hline $31 / 08 / 2008$ & $3 / 10 / 2008$ & 210 \\
\hline $30 / 09 / 2008$ & $30 / 04 / 2009$ & 390 \\
\hline $31 / 10 / 2008$ & $30 / 11 / 2009$ & 578 \\
\hline $30 / 11 / 2008$ & $30 / 06 / 2010$ & 0 \\
\hline
\end{tabular}

\section{Satisfaction / Use}

The satisfaction and use constructs were heavily challenged during the project. The users became very agitated and nervous when more and more errors and bugs cropped up while using the software. The user satisfaction dropped to a freezing cold when data inquiries took long execution times affecting also the response times, leaving the users with an enormous frustration towards the system. Sales invoices were not correctly assembled and printed which aggravated the users even more.

Usage of the inventory and the direct sales modules was not possible because of the software being not yet complete. Also the link with the accounting system was missing which led to a lot of manual work. Finally after more than a year since the last delivery and a standstill for several months, Blackbird lost all confidence in a good and final ending of the project. Blackbird edited a list with complaints, bugs and change requests, 45 in total and handed it over to Andreas. Some of the items on the list give some more information on the real situation of the IT artefact. Some of the most compelling items from the list are:

- We (Blackbird) have to propose everything to Andreas, even these things that we consider as evidently present in a business software...

- If we enter new a product in the system, we cannot see if the product is already created. So every now and then we create doubles...

- $\quad$ The system is halted for unknown reasons sometimes up to four or five times within a day. After each halt we have to reboot the system which takes a lot of time.

All items in the list where qualified by Andreas as change requests. The straw that broke the camel's back was the reaction of Andreas that the budget was spent and that from now on programming and debugging had to be paid extra.

There was also a very intense email communication between then users of Blackbird and the programmers of Andreas. The oldest emails were rather politely written and accordingly exchanged. However when the number of problems with the software increased, the style of the emails became more aggressive and fierce. 


\section{OISF}

By the middle of 2011, Blackbird ran out of patience and asked for a court order to obtain a contract dissolution with Andreas. They also requested a complete refund of the investment money that was contractually agreed and already paid to Andreas, an indemnity for losses due to the failure of the information system and the payment of all supplementary costs for the litigation. An extra damage of $€ 30.000$ was also asked because Blackbird had to pay a fine to the tax collector due to uncompleted annual reports from the information system. In their court order, the judges made the following assessment:

It is beyond reasonable doubt that the software that Blackbird has ordered from Andreas, is not fully operational, despite the numerous interventions between parties and specially these of Andreas. Although Blackbird claims that Andreas does not fulfil their contractual obligations and duties, this not proven, even more, Andreas makes in their defence the same claims, saying that Blackbird is neglecting the agreements made between the two parties. Although the court sees that a dispute has risen between the two parties, it does not known yet if there is enough evidence for a contract dissolution.

However the court took notice of the fact that Blackbird made a lot of complaints, sent by email, towards Andreas. Also the court sees that Blackbird has paid the price agreed in the contract. So the complaints cannot be ignored. Therefore the current situation with the information system needs some further investigation. An expert witness is needed to make the necessary observations.

The duty of the expert witness is to investigate if the complaints made by Blackbird have merit when an investigation of the information system is done. Therefore an expert witness will be ordered to conduct an Expert Assessment. The expert witness should give an answer to the following questions:

1. Invite all parties and take notices of their statements, oral as well as written.

2. Describe the information system

3. Describe all the performed work

4. Investigate if the performed work by Andreas is done according to 'art and best practices'

5. Describe the shortcomings and flaws and assign the accountabilities

6. Assess the damage

The expert witness is currently conducting his investigation and is also trying to reconcile the parties.

\section{Conclusions}

We used a narrative to understand the OISF that occurs between an SME-principal and an ISV-agent. In the building of our narrative we followed the OISF framework of Devos et al. (Devos et al. 2009a). The OISF framework was used as a theoretical guidance for making reflections and for structuring a chronology in the narrative. The case is taken from a litigation file of an OISF the was brought before court. 
As an overall observation we could see that the court (and the legal councillors of both parties) implicitly and a priori qualifies the collaboration between parties as a principal-agent agreement. This implies that already a mind-set is established with the stakeholders before the process of the OISF evaluation took place. As a researcher it is paramount to avoid that pitfall. Within a principal-agent setting an intense collaboration between parties is not always expected nor is a bi-directional information asymmetry assumed. On the contrary, the principal is primarily assumed to be the less informed party and the agent the most informed party. This is a biased assumption grounded in a belief that IS projects are mainly technological projects. The similarity in the terminology with construction projects is remarkable. However this is not entirely true for IS projects, which suggest a strong collaboration of the parties involved and where both parties also have to exchange hidden information before and during the project. The principal has to reveal as much as possible information on the actual flow of the current (and future) business processes. In this case we could observe that there was certainly not enough information available for Andreas to build a complete, ERP-like information system within the planned time and budget. On the other hand it was not clear if Blackbird was fully aware of their duty to describe as much as possible of the current requirements. However Andreas, as the most informed party on the techniques of conducting IS projects, had the obligation to perform a requirements elicitation and analysis study and should have forced Blackbird to participate in this. It looks as if both parties where unaware of the complexity and the granularity of all functions within the system. For Andreas it was one of their first ERP-like projects. Towards Blackbird they only send signals that indicate that they had control over the full project.

We could observe that the initial trust between the two actors gradual deteriorates when the project evolves. The selection of the ISV was almost entirely based on trust. In the principal-agent literature trust is not considered, only control is at stake (Devos et al. 2008). However it is shown that trust is major importance to avoid an OISF in SMEs (Devos et al. 2009b). Trust has been identified as an major construct in the success of partnerships, strategic alliances, and networks of firms (Das et al. 1998). The ISV, acting as the project leader seems to gradual lose control over the project and was captured within the strict boundaries of the fixed price contract. Andreas did not wanted to spend too much time on unclear requirements and focused more on clear and well written out ones. However it became more and more clear for both parties during the course of the project that the hope for frozen requirements was idle. This phenomenon was already discovered in electronic auctions and in IT outsourcing projects where a bidden party can make a too low bid so the entire project is jeopardized leading to relational problems (Kern et al. 2002).

First idle promises made by the agent towards the principal, to calm down and to hide the rudderless the project. But when the number of reported problems increase, the style revers and the communication became more and more accusatory. Although the principal sticks to the notion of trust, gradually the focus shifts to the fixed price contract as the ultimate and sole control measure.

The multi-voiced answers to the questions of the expert witness show not only the conflicts between the actors, but point to a deep gap between the perceptions and understandings of what constitutes an information system in an (SME) organization. The principal had a profound lack of IS/IT capabilities. We expressly make here a 
difference between IT (Information Technology) and IS (Information Systems). It can be assumed that profound knowledge of IT is not always needed for SMEs implementing an information system. But the IS managerial capabilities were not what could be expected from a CEO even of an SME. Although the CEO runs a small business, some understanding of the impact of an IS in an organization is paramount. On the other hand, the ISV had an obsession with IT and the conviction that the development and implementation of an IT artefact is purely based on positivist assumptions. The development method (Scrum) and the programs (code) got all the attention, but there no efforts were made to invest in the relation with the (unskilled) principal. A striking example of this gap was the enthusiasm shown by the ISV and his belief that he convinced the principal of using the Scrum method. Although the SME acknowledges the fact that Scrum was mentioned by the ISV he never understood what it was all about.

As compared with a strategic IT project conducted in a large organization, an IT project in an SME does not have so many stakeholders. This was also noticeable here. There were no groups of stakeholders with hidden expectations that could jeopardize the success of the project. As a consequence an in-depth stakeholders analysis with identification and evaluation of stakeholders and their expectations was easily made and done. The CEOs of both parties, as the major stakeholders were actively engaged in the project. Both CEO's had several roles in the project. The CEO of Blackbird took the roles of project leader and key user. The CEO of Andreas took the roles a project leader, business analysis, software architect and developer. This case shows that even with a limited amount of committed stakeholders an IT project can deteriorate quickly.

Another remarkable finding in this case is the very scarce documentation on the project proceedings. Even the contract and the proposal were not very elaborate on the project scope and objectives. The only written project documentation were printed emails exchanged between parties. It is clear that this kind of communication is extremely informal and offers not a good way to streamline a project. It looks like IT people have a profound problem with building up project documentation. Although there are methods available like PMBOK or Prince2 none of these method were even considered to be of use during the project. This is to our opinion a critical failure of most educational curricula in computer science. All too often the focus in graduate and undergraduate courses on IT/IS goes too much to the technological features of IS projects. The perspective of a socio-technical system is sometimes forgotten if not completely ignored. The multifaceted nature of human interaction suggests that straightforward application of empirical methods of natural science in organizations is problematic (Stowell 2008). The people from Andreas, all having a graduate degree in computer science, had a strong belief in the neutrality of technology and underestimated clearly the impact of the human factor. Moreover, people from Andreas tend to forget what Ciborra stated: 'that the real world has vague and murky contours' (Ciborra 2002). It is however not easy to understand organizations and the relation with IS since it is not possible to make laboratory replicates or simulations. Although the Scrum method claims to cope with these shortcomings in an innovative approach of the IS development process, the method implies a paradigm shift away from the more traditional 'waterfall' approaches. This is much harder to do then to learn the features of the method. The paradigm shift also implies that we incorporate failure 
into our methods and processes. According to Edmondson: "We are programmed at an early age to think that failure is bad. That belief prevents organizations from effectively learning from their missteps" (Edmondson 2011). However, we also belief that these more novel and iterative ways of building information systems are not so easily reconciled with a fixed price and time contract.

We may conclude that the OISF framework indeed shows a theoretical guidance for explaining an IT failure in an SME. The framework offers more than likely also such guidance for larger organization, however this has to be researched. We believe that in these cases the adjective 'larger' is better replace by 'more mature' organisations.

Finally, our study has some limitations. The generalization and replicability of the present study is constrained by the use of the single case study method. Since every case is unique we can only use theories to verify if data coming from a real-world case is consistent with the assumptions of these theories. In this study we used the framework for OISFs. Although the OISF framework is more a descriptive theory with less explaining and predicting power, we hope that the chronological sequence of events revealed by this narrative is helping in preventing future IS failures.

\section{References}

Admiraal, W., Lockhorst, D.: E-Learning in Small and Medium-sized Enterprises across Europe Attitudes towards Technology, Learning and Training. International Small Business Journal 27(6), 743-767 (2009)

Antlova, K.: Motivation and Barriers Of ICT Adoption In Small And Medium-Sized Enterprises. E \& M Ekonomie a Management 12(2), 140-155 (2009)

Aubert, B.A., Patry, M., Rivard, S.: A tale of two outsourcing contracts - An agency-theoretical perspective. Wirtschaftsinformatik 45(2), 181-190 (2003)

Avison, D., Gregor, S., Wilson, D.: "Managerial IT unconsciousness. Communications of the ACM 49(7), 89-93 (2006)

Barker, T., Frolick, M.N.: ERP implementation failure: A case study. Information Systems Management 20(4), 43-49 (2003)

Bartis, E., Mitev, N.: A multiple narrative approach to information systems failure: a successful system that failed. European Journal of Information Systems 17(2), 112-124 (2008)

Benbasat, I., Zmud, R.W.: The identity crisis within the is discipline: Defining and communicating the discipline's core properties. Mis Quarterly 27(2), 183-194 (2003)

Beynon-Davies, P.: Human error and information systems failure: the case of the London ambulance service computer-aided despatch system project. Interacting with Computers 11(6), 699-720 (1999)

Brown, A.D., Jones, M.R.: Doomed to failure: Narratives of inevitability and conspiracy in a failed IS project. Organization Studies 19(1), 73-88 (1998)

Bruner, J.: The Narrative Construction Of Reality. Critical Inquiry 18(1), 1-21 (1991)

Bruque, S., Moyano, J.: Organisational determinants of information technology adoption and implementation in SMEs: The case of family and cooperative firms. Technovation 27(5), 241-253 (2007)

Cerpa, N., Verner, J.M.: Why Did Your Project Fail? Communications of the ACM 52(12), 130-134 (2009) 
Chen, C.C., Law, C.C.H., Yang, S.C.: Managing ERP Implementation Failure: A Project Management Perspective. IEEE Transactions on Engineering Management 56(1), 157-170 (2009)

Ciborra, C.: The Labyrinths of Information: Challenging the Wisdom of Systems. Oxford University Press, USA (2002)

Conboy, K.: Project failure en masse: a study of loose budgetary control in ISD projects. European Journal of Information Systems 19(3), 273-287 (2010)

Cragg, P.B., King, M.: Small-Firm Computing - Motivators and Inhibitors. Mis Quarterly $17(1), 47-60$ (1993)

Cule, P., Schmidt, R., Lyytinen, K., Keil, M.: Strategies for heading off is project failure. Information Systems Management 17(2), 65-73 (2000)

Czarniawska, B.: Narrating the Organization. Chicago University Press, Chicago (1997)

Das, T.K., Teng, B.S.: Between trust and control: Developing confidence in partner cooperation in alliances. Academy of Management Review 23(3), 491-512 (1998)

Davidson, E.J.Y.: Examining Project History Narratives: An Analytic Approach. In: IFIP TC8 WG 8.2 International Conference on Information Systems and Qualitative Research, pp. 123-148. Chapman \& Hall, Ltd., Philadelphia (1997)

DeLone, W.H., McLean, E.R.: The DeLone and McLean model of information systems success: a ten-year update. Journal of Management Information Systems 19(4), 9-30 (2003)

Devos, J., Van Landeghem, H., Deschoolmeester, D.: Outsourced Information Systems Failures in SMEs: a Multiple Case Study. Electronic Journal of Information Systems Evaluation 11(2), 73-84 (2008)

Devos, J., Van Landeghem, H., Deschoolmeester, D.: IT Governance in SMEs: A Theoretical Framework Based on the Outsourced Information System Failure (2009a)

Devos, J., Van Landeghem, H., Deschoolmeester, D.: IT Governance in SMEs: Trust or Control? In: Dhillon, G., Stahl, B.C., Baskerville, R. (eds.) Information Systems - Creativity and Innovation in Small and Medium-Sized Enterprises, pp. 135-149 (2009b)

Devos, J., Van Landeghem, H., Deschoolmeester, D.: Rethinking IT governance for SMEs. Industrial Management \& Data Systems 112(1-2), 206-223 (2012)

Dibbern, J., Goles, T., Hirschheim, R.: Information Systems Outsourcing: A Survey and Analysis of the Literature. The DATA BASE for Advances in Information Systems 35(4), 6-102 (2004)

Dube, L., Pare, G.: Rigor in information systems positivist case research: Current practices, trends, and recommendations. Mis Quarterly 27(4), 597-635 (2003)

Edmondson, A.C.: Strategies for Learning from Failure. Harvard Business Review 89(4), 48 (2011)

Eisenhardt, K.M.: Agency Theory: An Assessment and Review. Academie of Management Review 14(1), 57-74 (1989)

Eisenhardt, K.M.: Better Stories and Better Constructs - The Case For Rigor and Comparative Logic. Academy of Management Review 16(3), 620-627 (1991)

Ewusi-Mensah, K.: Software Development Failures. MIT Press, Cambridge (2003)

Fincham, R.: Narratives of success and failure in systems development. British Journal of Management 13(1), 1-14 (2002)

Gable, G.G., Sedera, D., Chan, T.Z.: Re-conceptualizing information system success: The ISImpact measurement model. Journal of the Association for Information Systems 9(7), 377-408 (2008)

Group, S.: Third Quarter Research Report. The Standish Group International (2004) 
Huang, R., Zmud, R.W., Price, R.L.: Influencing the effectiveness of IT governance practices through steering committees and communication policies. European Journal of Information Systems 19(3), 288-302 (2010)

Iacovou, C.L., Dexter, A.: Surviving IT project cancellations. Communications of the ACM 48(4), 83-86 (2005)

Jensen, M.C., Meckling, W.H.: Theory of Firm - Managerial Behavior, Agency Costs and Ownership Structure. Journal of Financial Economics 3(4), 305-360 (1976)

Keil, M.: Pulling the plug: Software project management and the problem of project escalation. Mis Quarterly 19(4), 421-447 (1995)

Kern, T., Willcocks, L.P., van Heck, E.: The winner's curse in IT outsourcing: Strategies for avoiding relational trauma. California Management Review 44(2), 47 (2002)

Kreps, D., Richardson, H.: IS success and failure-the problem of scale. Political Quarterly 78(3), 439-446 (2007)

Lee, A.S.: Rigor and relevance in MIS research: Beyond the approach of positivism alone. Mis Quarterly 23(1), 29-33 (1999)

Lee, A.S., Baskerville, R.L.: Generalizing generalizability in information systems research. Information Systems Research 14(3), 221-243 (2003)

Lefebvre, L.A., Mason, R., Lefebvre, E.: The influence prism in SMEs: The power of CEOs' perceptions on technology policy and its organizational impacts. Management Science 43(6), 856-878 (1997)

Levy, M., Powell, P.: Strategies for Growth in SMEs: The Role of Information and Information Systems. Elsevier, Oxford (2005)

Lyytinen, K., Hirschheim, R.: Information-Systems Failures - A Survey and Classification of the Empirical Literature. Oxford Surveys in Information Technology (4), 257-309 (1987)

Mingers, J.: Combining IS research methods: Towards a pluralist methodology. Information Systems Research 12(3), 240-259 (2001)

Myers, M.D.: Qualitative research in information systems. Mis Quarterly 21(2), 241-242 (1997)

Natovich, J.: Vendor related risks in IT development: A chronology of an outsourced project failure. Technology Analysis \& Strategic Management 15(4), 409-419 (2003)

Riessman, C.K.: Narrative Analysis. SAGE Publications (1993)

Sauer, C.: Why Information Systems Fail: A Case Study Approach. Alfred Wailer, Henley-onThames (1993)

Schmidt, R., Lyytinen, K., Keil, M., Cule, P.: Identifying software project risks: An international Delphi study. Journal of Management Information Systems 17(4), 5-36 (2001)

Schwaber, K.: Agile Project Management with Scrum. Microsoft Press (2009)

Stowell, F.: Do We Mean Information Systems or Systems of Information? International Journal of Information Technologies and the Systems Approach 1(1), 25-36 (2008)

Thong, J.Y.L., Yap, C.S.: CEO Characteristics, Organizational Characteristics And Information Technology Adoption in Small Businesses. Omega-International Journal of Management Science 23(4), 429-442 (1995)

Verner, J.M., Abdullah, L.M.: Exploratory case study research: Outsourced project failure. Information and Software Technology 54(8), 866-886 (2012)

Wagner, E.L.: Interconnecting Information Systems Narrative Research: Current Status and Future Opportunities for Process-Oriended Field Studies. In: Wynn, E.A., Whitley, M., Myers, M., DeGross, J.I. (eds.) Global and Organizational Discourse About Information Technology, pp. 419-436. Kluwer Academic Publishers, Boston (2003) 
Wagner, E.L., Galliers, R.D., Scott, S.V.: Exposing Best Practices Through Narrative: The ERP Example. In: Kaplan, B., Truex, D., Wastell, D., Wood-Harper, T., D.J.I. (eds.) Information Systems Research: relevant Theory and Informed Practice, pp. 443-451. Kluwer Academic Publishers, Boston (2004)

Walsham, G.: Interpretive Case-Studies in is research - Nature and Method. European Journal of Information Systems 4(2), 74-81 (1995)

Webb, B., Mallon, B.: A method to bridge the gap between breadth and depth in IS narrative analysis. Journal of the Association for Information Systems 8(7), 368-381 (2007)

Weber, R.: The rhetoric of positivism versus interpretivism: A personal view. Mis Quarterly 28(1), III-XII (2004)

Welsh, J.A., White, J.F.: A Small Business Is Not A Little Big Business. Harvard Business Review 59(4), 18 (1981)

Yin, R.K.: Case Study Research: Design and Methods, 3rd edn. Sage Publications, Inc., Thousand Oaks (2003) 